\title{
Unavoidable myomectomy during cesarean section: a case report
}

\author{
Ayse Nur Aksoy ${ }^{1}$, Kemal Tolga Saracoglu ${ }^{2}$, Mehmet Aksoy ${ }^{3}$, Ayten Saracoglu ${ }^{4}$ \\ ${ }^{1}$ Department of Obstetrics and Gynecology, Nenehatun State Hospital, Erzurum, Turkey \\ ${ }^{2}$ Department of Anesthesiology and Reanimation, Marmara University School of Medicine, Istanbul, Turkey; \\ *Corresponding Author: saracoglukt@gmai; \\ ${ }^{3}$ Department of Anesthesiology and Reanimation, Nenehatun State Hospital, Erzurum, Turkey \\ ${ }^{4}$ Department of Anesthesiology and Reanimation, Uskudar State Hospital, Istanbul, Turkey
}

Received 28 December 2010; revised 15 February 2011; accepted 28 February 2011.

\begin{abstract}
Since myomectomy throughout cesarean delivery may lead to hemorrhage and uterinal atony, it is not recommended. But, myomectomy has been reported during cesarean section in recent studies. We presented a patient with large intramural myoma who was diagnosed at 34 weeks of pregnancy and operated with an unavoidable cesarean-combined myomectomy. A 33-year-old unpursued primigravida was referred to emergency department with abdominal pain and amenorrhea of 34 weeks duration. A sonographic diagnosis of myoma in pregnancy was made. Cesarean section was required for fetal distress and alive $2300 \mathrm{~g}$ weighted male infant with Apgar score of 6 at one minute, was born. As uterine incision could not be closed because of the myoma, myomectomy was performed dur- ing cesarean section unavoidably. A single $970 \mathrm{~g}$ and $15 \times 18 \mathrm{~cm}$ sized myoma was removed. The physical examinations were unremarkable in the postoperative period. Although there are case series that have demonstrated the safety of myomectomy during cesarean section, we concluded that myomectomy during cesarean section is not a safe procedure accept inevitable situations.
\end{abstract}

Keywords: Pregnancy; Cesarean Section; Myoma

\section{INTRODUCTION}

The incidence of uterine myomas varies from 0.3 to $7.2 \%$ during pregnancy (1). The size of myomas usually increases during pregnancy and may produce pressure injuries such as fetal malpresentation, hydronephrosis, preterm labour and torsion of uterus depending on num- ber, size and location of myomas. Because myomectomy throughout cesarean delivery may lead to hemorrhage and uterinal atony, is not recommended by some authors (2-4). It also carries increased risk of postoperative morbidity. On the other hand, some investigators suggested that myomectomy may be performed during cesarean section in selected patients (5-7).

In this case, we presented a patient with large intramural myoma who was diagnosed at 34 weeks of pregnancy and operated with cesarean-combined myomectomy.

\section{CASE REPORT}

A 33-year-old unpursued primigravida was referred to emergency department of Nenehatun Obstetrics and Gynecology Hospital with abdominal pain and amenorrhea of 34 weeks duration. The patient was examined vaginally and ultrasonographically. The procedure was carried out in accordance with the ethical standards and written informed consent was obtained from the patient. We conducted that she had regular uterine contractions, no cephalopelvic disproportion, $3 \mathrm{~cm}$ of cervical dilatetion, vertex presentation, 34 weeks of fetus, 150 /minute of fetal heart rate and about $15 \times 20 \mathrm{~cm}$ of abdominal mass. Primarily, we attempted for normal progress of labor. Whereas fetal distress appeared on the ultrasound doppler principle, we urgently decided for cesarean delivery. Blood test showed a hematocrit of 33\% and normal electrolytes levels. The patient's blood type was A Rhesus positive.

The patient was convinced to spinal anesthesia and pfannenstiel incision was performed. The uterinal structure was adequate for 34 weeks of gestation and the intramural myoma (15-17 cm in diameter) was situated through the muscle wall. Uterine cavity was distorted and lower uterine segment was deformed by myoma 
partially. A vertical uterine incision was made and alive male infant with Apgar score of 6 at one minute and $2300 \mathrm{~g}$ weighted was born. Uterine incision could not be closed because of the myoma. Then, the myometrium overlying the myoma was incised and pseudocapsule was dissected (Figure 1) by using electro-cautery to reduce blood loss. A single myoma measuring $15 \times 18 \mathrm{~cm}$ sized, 970 g weighted was removed (Figure 2). Hemostasis was achieved by 1-0 and 0 vicryl sutures (Figure 3). The serosa was sutured using absorbable suture (2-0 or 3-0 vicryl). Prophylactic antibiotics were used and the patient received antibiotics for seven days post-operatively. Approximately $700 \mathrm{ml}$ of blood loss was replaced by colloids without blood transfusion. The operation took place in 1.5 hours time. Intra-abdominal drain of hemovac was placed without vacuum. The postoperative hematocrit value was $30 \%$ and there were no maternal or fetal complications. The patient was discharged from the hospital at 8th postoperative day. The physical examinations

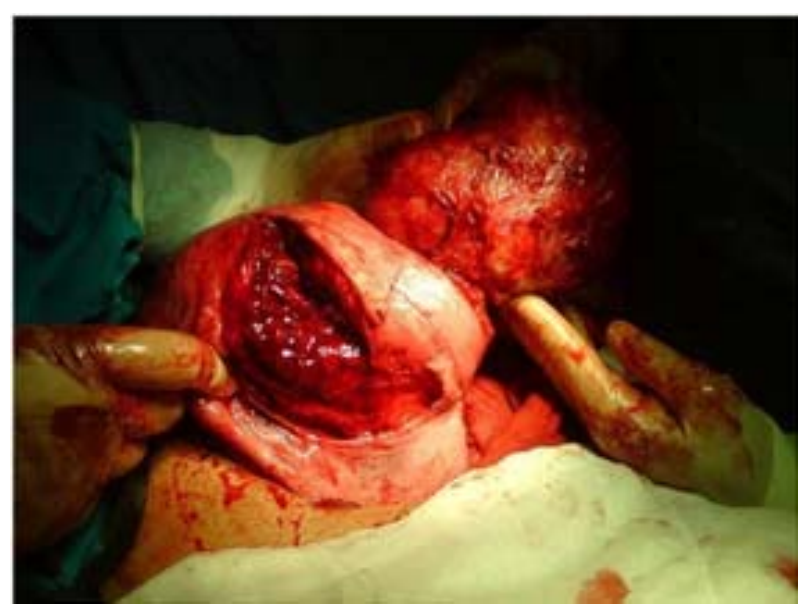

Figure 1. Dissection of the pseudocapsule and removing the myoma.

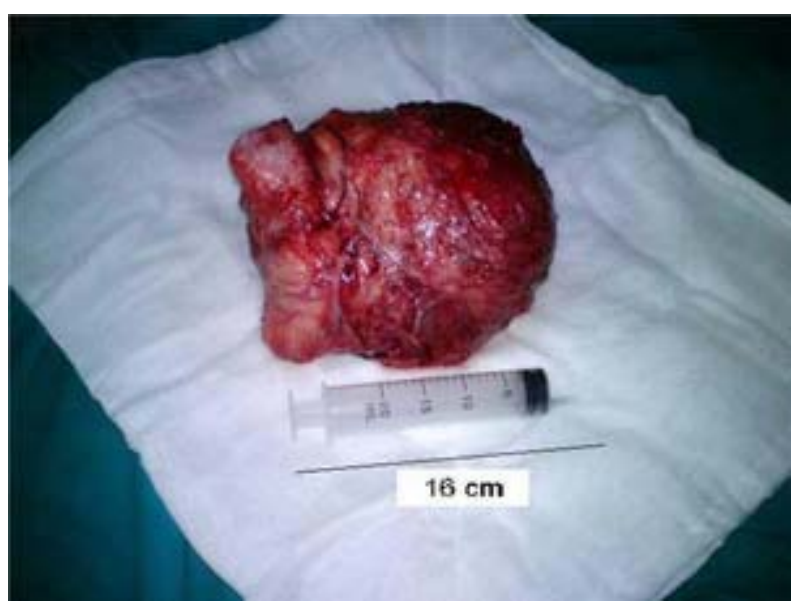

Figure 2. The appearance of myoma after removal.

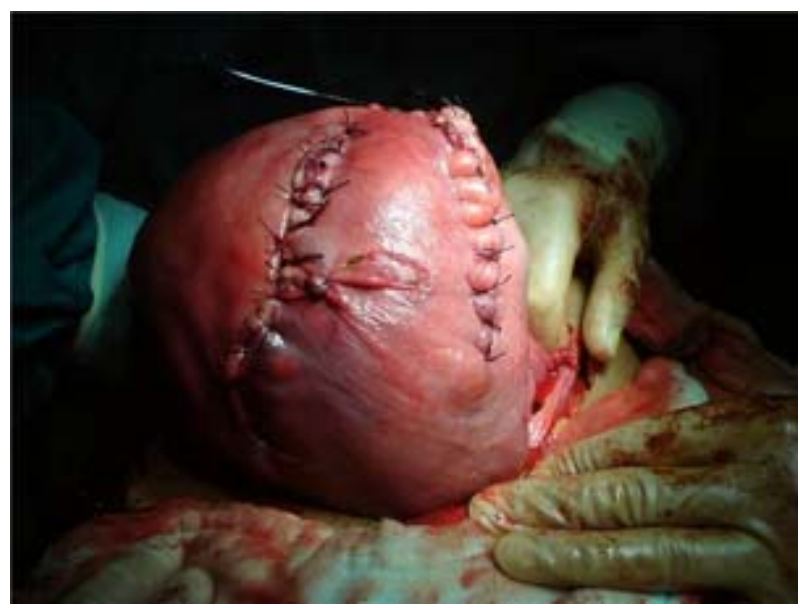

Figure 3. Final appearance after myomectomy.

were unremarkable in the four weeks period after hospitalisation.

\section{DISCUSSION}

Myomectomy is rarely performed during an ongoing pregnancy because of the risk of uncontrolled hemorrhage necessitating hysterectomy. In recent studies, Bhatla et al. (8) performed successful myomectomy in the second trimester for a large subserous fibroid, weighing 3900 g. Then the pregnancy continued uneventfully until term. Li $\mathrm{H}$ et al. (9) arised that mymectomy during cesarean section was a safe and effective procedure. Adesiyun et al. (10) investigated the fertility performance and pregnancy outcome in pregnants who had cesarean myomectomy at last delivery. They noticed no maternal or perinatal mortality factors. They suggested that the future fertility and or subsequent pregnancy outcome in patients were not affected by cesarean myomectomy.

Hassiakos et al. (11) previously investigated the simultaneous surgical removal of myoma diagnosed during cesarean section and they recommended that this procedure may be applied during cesarean section. Kaymak et al. (12) compared myomectomy during cesarean section with myomas and underwent alone. They found no significant diferences in the incidence of postoperative fever, hemorrhage and frequency of blood transfusion between myomectomy and control groups. They concluded that myomectomy can be performed without significant complications by experienced obstetricians during the cesarean section. In our case, we performed unavoidable myomectomy in cesarean surgery without blood transfusion and maternal complication. Because the reclosure of the abdomen was impossible, we performed mymectomy without any complication. However, possible life threatening complications such as 
hemorrhage or disseminated intravascular coagulation might ocur.

In conclusion, we do not always recommend but myomectomy during cesarean section may be performed in unavoidable conditions like in our present case.

\section{REFERENCES}

[1] Scott, J.R., Disaia, P.J., Hammond, C.B. and Spellacy, W.N. (1997) Danforth's Obstetrics and Gynecology. In: Creasman TW. Disorders of uterine corpus. 7th Edition, Lippincott-Raven Publishers, New York, 925-939.

[2] Ortac, F., Gungor, M. and Sonmezer, M. (1999) Myomectomy during cesarean section. International Journal of Gynecology \& Obstetrics, 67, 189-190. .doi:10.1016/S0020-7292(99)00129-0

[3] Davis, J.L., Ray-Mazumder, S., Hobel, C.J., Baley, K. and Sassoon, D. (1990) Uterine leimyomas in pregnancy: A prospective study. Obstetrics \& Gynecology, 75, 41-44.

[4] Hasan, F., Arumugam, K. and Sivanesaratnam, V. (1990) Uterine leimyomata in pregnancy. Int J Gynecol Obstet, 34, , 45-48. doi:10.1016/0020-7292(91)90537-F

[5] Kwawukume, E.Y. (2002) Myomectomy during cesarean section. International Journal of Gynecology \& Obstetrics, 76, 183-184. doi:10.1016/S0020-7292(01)00586-0

[6] Burton, C.A., Grimes, D.A. and March, C.M. (1989)
Surgical management of leimyomata during pregnancy. Obstetrics \& Gynecology, 74, 707-709.

[7] Roman, A.S. and Tabsh, K.M.A (2004) Myomectomy at time of cesarean delivery: A retrospective cohort study. BMC Pregnancy Childbirth, 16, 14-17. doi:10.1186/1471-2393-4-14

[8] Bhatla, N., Dash, B.B., Kriplani, A. and Aqarval, N. (2009) Myomectomy during pregnancy: A feasible option. Journal of Obstetrics and Gynaecology Research, 35, 173-175. doi:10.1111/j.1447-0756.2008.00873.x

[9] Li, H., Du, J., Jin, L., Shi, Z. and Liu, M. (2009) Myomectomy during cesarean section. Acta Obstetricia et Gynecologica Scandinavica, 88, 183-186. doi:10.1080/00016340802635526

[10] Adesiyun, A.G., Ojabo, A. and Durosinlorun, M.A. (2008) Fertility and obstetric outcome after caesarean myo- mectomy. Journal of Obstetrics and Gynaecology, 28, 710-712. doi:10.1080/01443610802462712

[11] Hassiakos, D., Christopoulos, P., Vitoratos, N., Xarchoulakou, E., Vaggos, G. and Papadias, K. (2006) Myomectomy during Cesarean Section: A Safe Procedure? Annals of the New York Academy of Sciences, 1092, 408-413. doi:10.1196/annals.1365.038

[12] Kaymak, O., Ustunyurt, E., Okyay, R.E., Kalyoncu, S. and Mollamahmutoglu, L. (2005) Myomectomy during cesarean section. International Journal of Gynecology \& Obstetrics, 89, 90-93. doi:10.1016/j.ijgo.2004.12.035 